\title{
Regional workshop on healthy diet with a focus on trans-fatty acid elimination ${ }^{1}$
}

Citation: Regional workshop on healthy diet with a focus on trans-fatty acid elimination. East Mediterr Health J. 2019;25(11):847-848 https://doi. org/10.26719/2019.25.11.847

Copyright @ World Health Organization (WHO) 2019. Some rights reserved. This work is available under the CC BY-NC-SA 3.0 IGO license (https:// creativecommons.org/licenses/by-nc-sa/3.o/igo).

\section{Introduction}

The Eastern Mediterranean Region of the World Health Organization (WHO) has experienced an epidemiological and nutritional transition in recent years. People in the Region are now consuming more foods that are high in fats, free sugars or salt/sodium, while many do not eat enough fruit, vegetables and dietary fiber such as wholegrains (1). This has contributed to high rates of overweight and obesity in the Region: nearly two-thirds $(60.1 \%)$ of adult females and more than half $(52.8 \%)$ of adult males are overweight or obese (1). The Region also suffers from an early childhood overweight and obesity rate of $6.8 \%$ - well above the global average of $5.6 \%$. In some countries, more than $11 \%$ of children are affected. Furthermore, in many countries more than a quarter of adolescents are overweight or obese (1).

Across the Region, national plans and strategies are being implemented to improve nutrition and prevent obesity through intersectoral policies, such as: restricting the marketing of unhealthy foods to children; integrating healthy diets within school food policies; taxing sugarsweetened beverages; stimulating physical activity; and pursuing community-based approaches. However, countries are struggling to implement these plans fully, and renewed focus is required to assess the current situation, identify key challenges and gaps, and devise practical and strategic action plans (2).

A regional workshop on healthy diet with a focus on trans-fatty acid elimination was organized by the Regional Office in Beirut, Lebanon, from 19 to 21 March 2019 (3). The multisectoral workshop was attended by participants from 15 countries of the Region, and included representatives from academia, United Nations Children's Fund (UNICEF), World Food Programme (WFP), Food and Agriculture Organization (FAO), United Nations Relief and Works Agency for Palestine Refugees in the Near East (UNRWA), and from nongovernmental organizations.

The objectives of the workshop were to:

- share WHO policies and strategies on eliminating trans-fatty acids and reducing salt, fat and free sugar intakes;
- share success stories and progress achieved at the global and regional levels in reducing trans-fatty acids, salt, fat and sugar intakes;

- identify challenges and possible solutions to reduce trans-fatty acids, salt, fat and sugar intakes;

- develop/review national plans for implementing healthy diets and nutrition strategies;

- enhance multisectoral coordination with clear roles and responsibilities for every actor.

\section{Summary of discussions}

Progress in the elimination of trans-fatty acids and reduction of salt, fat and sugar intakes was reported from the Region in a number of areas. Five countries have implemented an effective tax on sugar-sweetened beverages: Islamic Republic of Iran, Morocco, Oman, Saudi Arabia and United Arab Emirates. Four countries have implemented or revised standards for nutrition labelling to include mandatory front-of-package nutrition labelling for all pre-packaged foods: Islamic Republic of Iran, Morocco, Saudi Arabia and Tunisia. A number of countries are conducting appropriate campaigns on healthy diets, including Egypt (the 100 Million Health Campaign), Kuwait, Morocco, Palestine and Saudi Arabia.

A number of countries have developed, or are in the process of developing, national nutrition strategies or plans. Egypt has developed a national multisectoral action plan for noncommunicable diseases and is developing a national nutrition strategy; Saudi Arabia has developed a healthy foods strategy; Kuwait and Lebanon are developing national food-based dietary guidelines; Morocco has developed a national nutrition strategy and national plan for the prevention and control of noncommunicable diseases; and Tunisia has developed a national strategy to prevent obesity and control noncommunicable diseases (4).

However, there are challenges to the elimination of trans-fatty acids from food products in the Region and to reducing salt, fat and sugar intakes. In most countries of the Region, accurate data are not available and market surveys on the amount of added sugars, salts and transfatty acids present in food products are lacking. There is 
also minimal data regarding the level of risk exposure of the Region's population, particularly children and adolescents, to industrially produced trans-fatty acids and saturated fatty acids in processed foods. In addition, a lack of regional expertise to conduct high-quality research on nutrition and limited available funds are further challenges currently faced.

\section{Recommendations}

\section{To WHO}

- Providing technical support to civil society and private sector actors including nutrition education, methodology for conducting epidemiological studies and capacity building.

- Collaborating with academic and research institutions to develop methodology for nutrition research, conducting epidemiological/analytical studies and situation analysis.
- Providing technical support for mapping food products and levels of trans-fatty acids, saturated fats, sodium/salt and free sugars in foods.

- Providing technical support to countries for the development of national nutrition strategies and plans.

\section{To Member States}

- Encouraging and supporting civil society, nongovernmental organizations and the private sector to engage in the process by reviewing legislations, and providing decision-makers and policy-makers with nutrition reports regarding food quality and safety.

- Monitoring the implementation of national nutrition strategies and plans, and providing technical support to ensure their sustainability.

- Facilitating funding, as needed, to implement nutrition action plans.

\section{References}

1. World Health Organization Regional Office for the Eastern Mediterranean (WHO/EMRO). Obesity. Cairo: WHO/EMRO; 2018 (http://www.emro.who.int/health-topics/obesity/).

2. World Health Organization. Framework for the implementation of the global strategy on diet, physical activity and health in the Eastern Mediterranean Region. Geneva: World Health Organization; 2010 (http://applications.emro.who.int/dsaf/emropub_2010_1273.pdf?ua=1).

3. World Health Organization Regional Office for the Eastern Mediterranean (WHO/EMRO). Summary report on the regional workshop on healthy diet with a focus on trans-fatty acid elimination. Cairo: WHO/EMRO; 2019 (http://applications.emro.who. int/docs/EMROPUB_2019_EN_23812.pdf?ua=1).

4. World Health Organization Regional Office for the Eastern Mediterranean (WHO/EMRO). Regional strategy on nutrition 2010-2019 and plan of action. Cairo: WHO/EMRO; 2011 (http://applications.emro.who.int/dsaf/dsa1230.pdf?ua=1). 